\title{
SPATIAL CHARACTERISTICS OF URBAN GREEN SPACE: A CASE STUDY OF SHANGHAI, CHINA
}

\author{
ZHANG, L. ${ }^{1,2}-$ WANG, Z. ${ }^{1,2}-$ DA, L. ${ }^{1,2^{*}}$ \\ ${ }^{1}$ School of Ecological and Environmental Sciences, East China Normal University, Shanghai \\ 200241, China \\ ${ }^{2}$ Shanghai Key Laboratory for Ecology of Urbanization Process and Eco-Restoration, Shanghai \\ 200241, China \\ ${ }^{*}$ Corresponding author \\ e-mail: ljda@des.ecnu.edu.cn \\ (Received 28 $8^{\text {th }}$ Sep 2018; accepted $28^{\text {th }}$ Nov 2018)
}

\begin{abstract}
In China, rapid urbanization has profoundly transformed the spatial pattern of urban land use, including urban green spaces. The government plans to optimize green spaces to integrate them with urban development; this requires an understanding of the process of green space change. Quantifying landscape pattern and its change is essential for monitoring and assessing ecological consequences of urbanization. In this study, the moving window method and gradient analysis were used to analyze highresolution satellite images and interpret Shanghai urban green space distribution data. A window of $5 \mathrm{~km}$ was found to be a rational size that can reflect urban green space patterns via changes in landscape metrics. Green space patterns can be quantified through gradient analysis and landscape metrics. Different types of green space exhibit obvious "spatial characteristics" along the landscape pattern gradient. Urban green space distribution patterns can be used to verify the urban space development mode. The 'concentric circle' development theory was applicable to the urban development of Shanghai. The research provides significant guidance for further study on the interrelations of urban green space pattern processes, for examination and assessment of urbanization processes and for urban planners and decision makers.
\end{abstract}

Keywords: landscape pattern, spatial extents, gradient analysis, landscape index, urban green space

\section{Introduction}

With the accelerated progress of globalization and urbanization, urban issues (such as urban shape and evolution) have become very topical issues across the world (Breuste et al., 1998; Pickett et al., 2001; Whitford et al., 2001). In 1940, only $8 \%$ of the global population lived in downtown areas. By the year 1980, more than one third of the population was living in urban areas (World Commission on Environment and Development, 1987). Experts predict that by the year 2025, 60\% of the world population will be living in cities (Schell and Ulijaszek, 1999). With the rapid growth of population, downtown areas within cities develop quickly and the urban areas increase tremendously as well; this growth results in various modes of city development. The morphology and evolution of cities have been extensively studied by geographers, economists, and social scientists for centuries (von Thünen, 1825; Christaller, 1933; Hoyt, 1939; Harris and Ullman, 1945; Lösch, 1954; Wilson, 1976; Allen and Sanglier, 1979; Tobler, 1979; Wilson, 1981; Couclelis, 1985; Batty et al., 1989; Wong and Fotheringham, 1990; White and Engelen, 1993; Batty, 1997; Schweitzer, 1997; Portugali, 2000). The changes in urban morphology will have a profound and farreaching influence in the urban environment, especially the transformation of urban green landscapes (Gordon, 1990). Furthermore, green land plays a critical role in urban 
development. Thus, the rationality and scientific validity of urban green land distribution is a criterion for judging a city's sustainable development (Chiesura, 2004). At the same time, governments are beginning to recognize the importance of healing the rift between humans and nature. Planners, designers and researchers are in need of valid tools for making quantitative assessments and analyses of reasonable development models with the aim of giving a stronger scientific basis for decisions about urban development.

In previous research on urban shape and evolution, landscape pattern analysis has increasingly been applied to examine urban issues (Kong and Nobukazu, 2006). The window movement method and the gradient analysis method, both based on FRAGSTATS software (http://www.umass.edu/landeco/research/fragstats/fragstats.html) are especially widely used. A landscape index has been widely applied to analyze the urban landscape pattern quantitatively (Pickett et al., 1997, 2001; Whitford et al., 2001; Kong and Nobukazu, 2006). Gradient analysis is now repeatedly adopted in research aimed to investigate the influence of urbanization on urban morphology development (Whittaker, 1975; Kowarik, 1990; Pouyat and McDonnell, 1991; Pouyat et al., 1995; Frohn, 1998; Sukopp, 1998; Zhu and Carreiro, 1999; Wu, 2000; McGarigal and Cushman, 2008). For instance, Luck and Wu (2002) found that the spatial pattern of urbanization can be studied quantitatively by combining gradient analysis and a landscape index. Kong and Nobukazu (2006) utilized these methods of gradient analysis and landscape index to show that the urbanization had changed greatly Jinan's land use types. Li et al. (2004) utilized the landscape pattern index and gradient analysis method to research the landscape structure of Shanghai and the effects of its spatial characteristics on urbanization gradient; results showed that the farmland was the dominant landscape, accounting for about $60 \%$ of the landscape. Zhang et al. (2008) also combined the two methods to analyze changes in the landscape index under different extents in Huizhou city of Guangdong Province. However, these studies examined the range of a whole city region and different land types (Luck and $\mathrm{Wu}, 2002$; Zhu et al., 2006). Research using the gradient analysis method and landscape index to study urban green space patterns is limited. Therefore, the use of these two methods to study the pattern of urban green space has a very important significance.

Shanghai, as a megalopolis in China, is undergoing rapid urbanization. A series of problems (such as short-term high-density investment, population explosion, industrial concentration, rapid urbanization of suburbs, and high-strength development features of increased building density and plot ratio) arising from urbanization are being developed at the sacrifice of urban green space and agricultural land and could endanger the sustainable development of Shanghai. One of the urgent issues to be solved by Shanghai is how to optimize the land utilization pattern to meet the land demand for residential, industrial and urban greening purposes. This must be accomplished while also addressing the impact of unlimited expansion of urban space on the urban ecological system and its ecological result during the process of urbanization. The landscape pattern index is an important tool for quantitative analysis of landscape space dynamics and has played an important role in urban ecology and urban landscape research in recent years (Luck and $\mathrm{Wu}, 2002$; Zhang et al., 2004).

In the current study, high resolution remote sensing images were used to interpret urban green space vector diagrams. With the help of a geographic information system (GIS), a gradient analysis was conducted of the landscape belt transect across 
downtown Shanghai, China. The objectives were to illustrate the space pattern characteristics of Shanghai's urban green space landscape, examine the extent of change in various green space landscapes using gradient analyses, and study the changes of landscape metrics in landscape stratification along the belt transect under different extents. Three main questions were studied. (1) What is the rational extent for the gradient analysis of Shanghai urban green space landscape pattern? (2) Do different urban green spaces have unique spatial characteristics? (3) What is the development pattern of Shanghai urban space? The research was intended to provide a scientific basis for further optimization of the landscape pattern and construction of an urban green space landscape system with a rational structure, scientific layout and ecological benefit.

\section{Materials and Methods}

The Shanghai metropolitan region $\left(30^{\circ} 23^{\prime}-31^{\circ} 37^{\prime} \mathrm{N}, 120^{\circ} 50^{\prime}-121^{\circ} 45^{\prime} \mathrm{E}\right)$ is located on the eastern coast of China, with the Yangtze River estuary to the north, the East Sea to the east and Hangzhou Bay to the south (Fig. 1a). The region has an area of 6,340 $\mathrm{km}^{2}$ and a population of 24.1527 million. Shanghai has a northern subtropical monsoon climate, with an average annual temperature of $16^{\circ} \mathrm{C}$; however, summer temperatures average $28^{\circ} \mathrm{C}$, while the winters are cold with an average temperature of $4^{\circ} \mathrm{C}$. Average annual precipitation is approximately $1,200 \mathrm{~mm}$, with $60 \%$ of the annual rainfall occurring during May-September.

The research area was mainly located within the outer ring road of Shanghai and had an area of $660 \mathrm{~km}^{2}$. Included in the study area were Yangpu District, Hongkou District, Zhabei District, Jing'an District, Huangpu District and Luwan District, and partial areas of Putuo District, Changning District, Minhang District, Xuhui District, Baoshan District and Pudong New Area (Fig. 1b).

Shanghai has proposed a strategy of building a forested city, with the focus on constructing urbanized areas and public green space at various levels to form a greening network described as "surrounded by forest, internal greening network". The strategy is intended to realize the purpose of urban area greening through a large cycle of "ring, wedge, corridor, garden and forest". The network will situate the city in a forest to surround people with green area so as to lay a foundation for "Shanghai in forest" and "green Shanghai". Therefore, research on Shanghai's urban green space pattern is of great importance for urban greening construction in the city.

Primary data sources used in the study included: (1) 2015 Landsat-8 images (resolution $30 \mathrm{~m}$; bands 6, 5 and 4); (2) Shanghai city image atlas in 2015 and 1:28,000 greater Shanghai map in 2015; and (3) urban planning data obtained from the Shanghai Planning Bureau and the Statistics Bureau (auxiliary information).

Green land information for Shanghai in 2015 was obtained using ArcInfo software (Version 8.2, ESRI, Redlands, CA, USA) as well as visual interpretation to classify green land. In addition, a field survey and data adjustment helped to define the urban green type vector diagram with attribute data and the corresponding spatial data. At various spatial scales $(3 \mathrm{~km}, 4 \mathrm{~km}, 5 \mathrm{~km}, 6 \mathrm{~km}$ and $7 \mathrm{~km}), 160$ belt transects were established in the directions from north to south and east to west; 320 sampling points were identified as well (Fig. 1c). The classification of urban green space types was determined using the Standard for Classification of Urban Green Spaces (CJJ/T852002) of the Ministry of Housing and Urban-Rural Development. The specific urban 
green land function and characteristics were determined, as well as the types of land use, ownership, and physical factors (colors, tones, location, size and texture) (Fig. 1c). The accuracy of grading different urban green land samples was $97.5 \%$, which was considered acceptable. ArcMap (Version 8.2, ESRI) was used for spatial analysis and for transforming the vector data of green land types into the raster format in $2 \times 2 \mathrm{~m}$ pixel areas.
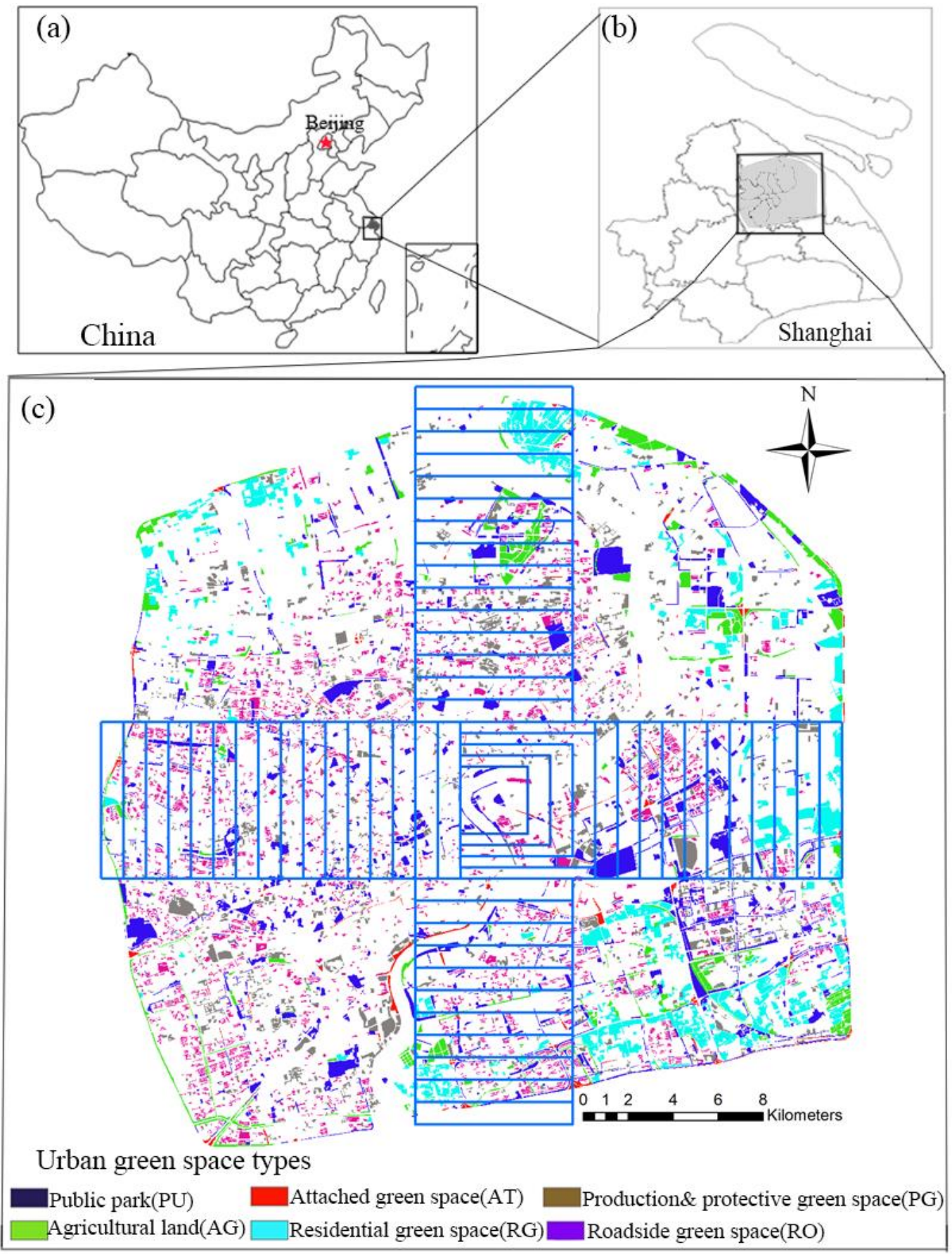

Figure 1. The study area showing: (a) location of Shanghai city in China; (b) regional location of Shanghai City; (c) urban green space map of Shanghai City and transects of windows used to sample green space 
Based on the Standard for Classification of Urban Green Spaces (CJJ/T85-2002) of the Ministry of Housing and Urban-Rural Development, and in combination with Shanghai's urban green space characteristics, Shanghai's urban green spaces were divided into six categories, as follows:

- Public park (PU) - this type of green space included comprehensive parks, citywide parks, regional parks, community parks, parks in residential areas, gardens and parks in residential quarters, theme parks, children's parks, zoos, botanic gardens, historical gardens and parks, scenic spots, amusement parks, other theme parks, and belt-shaped parks.

- Residential green space (RG) - this type of green space included residential quarters and communities.

- Attached green space (AT) - this type of green space included public facilities, industrial green space, green space for warehousing, green space for external traffic, green space for municipal facilities, and special green space.

- Roadside green space (RO) - this type of green space included roadside verges and similar green fields.

- Production and protective green space (PG) - this type of green space included green space for production and protection.

- Agricultural land (AG) - this type of green space included cultivated land, garden plots, forest land, grassplots, agricultural land for facilities, field ridges, and country roads.

Identification of each green space type was determined (in combination with the comprehensive analysis of the specific situation of Shanghai) based on the features of the spaces that were visible on the remote sensing image including color, tone, shape, position, size and texture.

The combined method of gradient analysis and landscape metrics was used in the study. "Windows" of various sizes $(3 \mathrm{~km}, 4 \mathrm{~km}, 5 \mathrm{~km}, 6 \mathrm{~km}$ and $7 \mathrm{~km}$ ) were used to move along a selected belt transect and analyzes the landscape pattern changes so as to identify the urban green space landscape pattern and its gradient change. The Lujiazui central green space was the central window. The spatial step of each window along a transect was $1 \mathrm{~km}$ and windows moved from west to east and from south to north, obtaining a series of land pattern samples of various sizes. The central window location was the origin $(0 \mathrm{~km})$. Movements toward the east and north were designated positive values and toward the south and west were negative values. Land pattern characteristics were calculated using a 1-km sliding step to correct for noise caused by small scale and local variations, a technique similar to the analysis of time series data (Fig. 1c). ArcMap software (ESRI) was used to digitally cut the sample belts from the Shanghai green space vector diagram and convert them into $2-\mathrm{m} \times 2-\mathrm{m}$ grid (raster) data for visual presentation.

The FRAGSTATS 4.2 software (McGarigal, 2002) was used to determine the correlation pattern characteristic index of green space landscape (McGarigal and Marks, 1995). The redundancy and overlap among landscape metrics have been investigated previously (e.g., O’Neill et al., 1999). Not all the available landscape metrics were needed to capture the changes in the composition and configuration of the landscape. A small set of metrics (13 in total) were chosen to be both sensitive to changes and numerically reliable (i.e., showing consistent trends) for depicting landscape patterns (Table 1). As in most cases in the existing literature, the term "landscape pattern" in this study included both the non-spatial composition (e.g., the number and relative 
abundance of patch types, patch size, and other related non-spatial measures) and spatial configuration (e.g., patch shape, juxtaposition, contrast, and boundary characteristics). $\mathrm{Li}$ and Reynolds (1994) defined spatial heterogeneity in a similar way.

Specifically, 10 indices were used as compositional measures: percentage of landscape (PLAND), patch density (PD), edge density (ED), patch richness (Hobbs, 1988) (PR), Shannon diversity index (SHDI), largest patch index (LPI), mean patch size (MPS), aggregation index (AI), patch size standard deviation (PSSD) and patch size coefficient of variation (PSCV). The remaining three indices were used as configurational measures: landscape shape index (LSI), area-weighted mean shape index (AWMSI) and area-weighted mean fractal dimension (AWMFD) (O'Neill, 1988). This dichotomy of compositional versus configurational indices is apparently an oversimplification, and many of these indices reflect both aspects of landscape pattern to varying degrees (McGarigal and Marks, 1995). However, this simple classification scheme was adopted so as to facilitate the organization of results and their interpretation.

Table 1. Landscape metrics used to quantify the spatial pattern of urbanization in metropolitan Shanghai, China (based on McGarigal and Marks, 1995)

\begin{tabular}{|c|c|c|}
\hline Landscape metrics & Abbreviation & Description \\
\hline \multicolumn{3}{|c|}{ Compositional measures } \\
\hline Percentage of landscape (\%) & PLAND & $\begin{array}{l}\text { The proportion of total area occupied by a particular patch } \\
\text { type; a measure of dominance of patch types }\end{array}$ \\
\hline Patch density & PD & The number of patches of per 100 ha \\
\hline Edge density $\left(\mathrm{m} \mathrm{ha}^{-1}\right)$ & ED & $\begin{array}{l}\text { The total length of all edge segments per hectare for the } \\
\text { class or landscape of consideration }\end{array}$ \\
\hline Patch richness & PR & $\begin{array}{l}\text { The number of patch types in the landscape; a measure of } \\
\text { diversity of patch types }\end{array}$ \\
\hline Shannon diversity index & SHDI & $\begin{array}{l}\text { A measure of patch diversity in a landscape, which is } \\
\text { determined by both the number of different patch types and } \\
\text { the proportional distribution of area among patch types }\end{array}$ \\
\hline Largest patch index (\%) & LPI & $\begin{array}{c}\text { The ratio of the area of the largest patch to the total area of } \\
\text { the landscape }\end{array}$ \\
\hline Mean patch size (ha) & MPS & The average area of all patches in the landscape \\
\hline Aggregation Index & $\mathrm{AI}$ & $\begin{array}{l}\text { The aggregation index reflects the patches in the landscape } \\
\text { and the index of the decentralized state }\end{array}$ \\
\hline $\begin{array}{l}\text { Patch size standard deviation } \\
\text { (ha) }\end{array}$ & PSSD & The standard deviation of patch size in the entire landscape \\
\hline $\begin{array}{l}\text { Patch size coefficient of } \\
\text { variation }(\%)\end{array}$ & PSCV & $\begin{array}{l}\text { The standard deviation of patch size divided by mean patch } \\
\text { size for the entire landscape }\end{array}$ \\
\hline \multicolumn{3}{|c|}{ Configurational measures } \\
\hline Landscape shape index & LSI & $\begin{array}{l}\text { The total length of patch edges within the landscape } \\
\text { divided by the total area, adjusted by a constant for a } \\
\text { square standard }\end{array}$ \\
\hline $\begin{array}{l}\text { Area-weighted mean shape } \\
\text { index }\end{array}$ & AWMSI & Mean patch shape index weighted by relative patch size \\
\hline $\begin{array}{l}\text { Area-weighted mean fractal } \\
\text { dimension }\end{array}$ & AWMFD & The patch fractal dimension weighted by relative patch area \\
\hline
\end{tabular}

\section{Results}

\section{Synoptic characteristics of the Shanghai area landscape}

Data in Table 2 show the six categories used to distinguish green space in Shanghai. PU had the largest PLAND (up to 30.32\%), and its PSCV value (278.15\%) was also relevantly large, indicating that PU was the dominant green space type in the belt 
transects. AT had the second largest PLAND (26.46\%) and the proportions of RG, AG, PG and RO decreased (in that order) such that RO occupied the smallest proportion $(2.46 \%)$ of the sampled area. PD (the number of patches per unit area) reflects the degree of landscape breakage; i.e., the larger is PD, the smaller are the patches and the higher is the degree of fragmentation. The PD of RG was the largest and far higher than that of other green space types; AT had the most scattered distribution and highest degree of fragmentation among the belt transects. AG had the largest LPI (1.25\%) and the largest AI (87.25\%), indicating that AG green space was concentrated with a low degree of fragmentation.

The PD and LSI of the entire landscape were relevantly large, indicating that the overall degree of breakage of Shanghai urban green space was relevantly large and Shanghai was comprised of complex green space patch shapes. The AI of RO was the smallest of all green space types, and RO consisted of small areas and scattered distribution. The Shannon diversity index of the entire belt transect was 1.65 , indicating a low level of diversity.

Table 2. Class and landscape-level metrics of the land use transects

\begin{tabular}{|c|c|c|c|c|c|c|c|}
\hline \multirow{2}{*}{ Landscape metrics } & \multicolumn{6}{|c|}{ Types } & \multirow{2}{*}{$\begin{array}{c}\text { Landscape } \\
\text { level }\end{array}$} \\
\hline & $\mathbf{P U}$ & RO & RG & AT & PG & AG & \\
\hline $\begin{array}{l}\text { Percentage of } \\
\text { landscape }(\%)\end{array}$ & 30.32 & 2.46 & 18.08 & 26.46 & 6.94 & 15.74 & - \\
\hline $\begin{array}{l}\text { Patch density } \\
\left(\mathrm{No} / 100 \mathrm{hm}^{2}\right)\end{array}$ & 8.34 & 3.20 & 13.55 & 6.87 & 1.63 & 0.93 & 37.77 \\
\hline $\begin{array}{c}\text { Largest patch index } \\
(\%)\end{array}$ & 2.54 & 0.18 & 1.40 & 0.36 & 0.6235 & 1.25 & 4.34 \\
\hline Edge density (m/ha) & 3.23 & 0.77 & 1.60 & 2.27 & 1.12 & 0.50 & 4.75 \\
\hline $\begin{array}{c}\text { Landscape shape } \\
\text { index }\end{array}$ & 36.53 & 22.37 & 31.59 & 59.13 & 17.84 & 15.54 & 77.43 \\
\hline $\begin{array}{l}\text { Patch size coefficient } \\
\text { of variation }(\%)\end{array}$ & 278.15 & 176.615 & 236.06 & 146.54 & 231.16 & 269.14 & 365.74 \\
\hline $\begin{array}{l}\text { Area-weighted mean } \\
\text { shape index }\end{array}$ & 2.017 & 1.99 & 1.937 & 2.18 & 2.52 & 4.15 & 2.41 \\
\hline $\begin{array}{c}\text { Aggregation Index (\% } \\
)\end{array}$ & 77.53 & 51.85 & 74.92 & 74.18 & 60.63 & 87.25 & 74.30 \\
\hline $\begin{array}{c}\text { Shannon diversity } \\
\text { index }\end{array}$ & - & - & - & - & - & - & 1.65 \\
\hline
\end{tabular}

\section{Gradient analysis with landscape-level metrics at different spatial extents}

Although there is a large amount of literature about the use of landscape gradients, the study area does not conform entirely to previously used methodology. Therefore, a rational spatial extent had to be chosen for analyzing the land use pattern in Shanghai. Based on the literature, five spatial extents were selected $(3 \times 3 \mathrm{~km}, 4 \times 4 \mathrm{~km}, 5 \times 5 \mathrm{~km}$, $6 \times 6 \mathrm{~km}$ and $7 \times 7 \mathrm{~km}$ ) to study the gradient distribution characteristics of Shanghai urban green space landscape pattern in an attempt to find the window size that was most appropriate.

Based on the landscape metrics at various spatial extents, PD, MPS, LSI and AWMSI exhibited obvious gradient change trends (Figs. $2 b, 2 c, 2 e$ and $2 f$ ). Among these indices, PD gradually decreased from west to east and the highest value occurred at $-8 \mathrm{~km}$ to -2 $\mathrm{km}$ from the origin. This area was the old city of Shanghai with small and scattered landscape green spaces indicating a high degree of breakage in the landscape (Fig. 2b). MPS gradually increased from west to east along the belt transect and displayed a J- 
shaped distribution; this distribution indicated that the areal extent of a single patch from west to east of the city gradually increased and was highly concentrated at the urban suburbs. Furthermore, there was a concentration of either of two types of green space based mainly on large patch green space (such as AG) with low breakage degree (Fig. 2c).
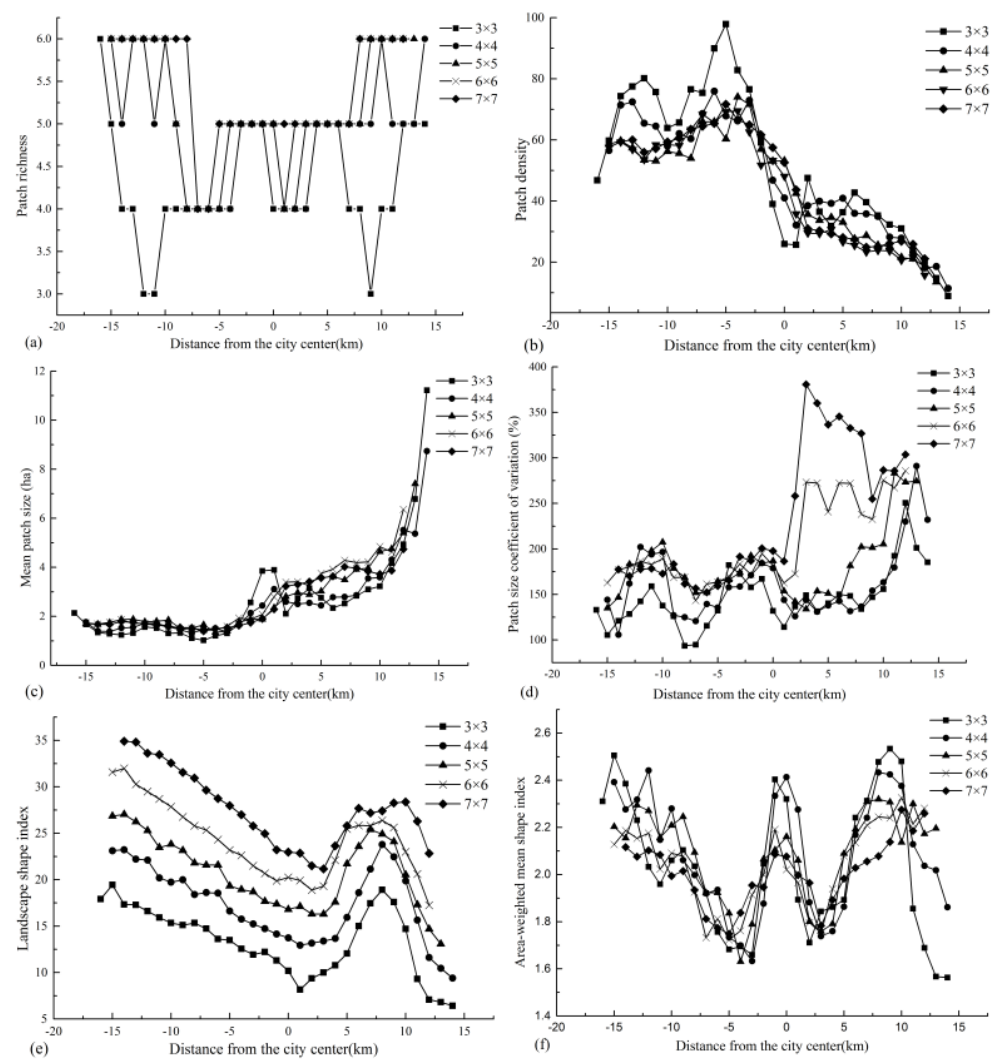

Figure 2. Variation of landscape metrics along the east-west direction land use transect at different spatial extents: (a) patch richness, (b) patch density, (c) mean patch size, $(d)$ patch size coefficient of variation, $(e)$ landscape shape index, and $(f)$ area-weighted mean shape index. To examine the effect of changing scale of analysis, five window sizes were used: $3 \times 3 \mathrm{~km}, 4 \times 4$

$\mathrm{km}, 5 \times 5 \mathrm{~km}, 6 \times 6 \mathrm{~km}$ and $7 \times 7 \mathrm{~km}$ blocks. See text for details

LSI gradually decreased from west to east along the belt transect with the valley at -2 to $+4 \mathrm{~km}$ from the center and peaked at $+9 \mathrm{~km}$; this occurred because at a distance of -16 to $-4 \mathrm{~km}$, there was a gradual transition from urban suburbs to the old city. The proportion of RG in the living area of the urban suburbs was large and, the larger the LSI value, the more dispersed were the green space patches. The peak occurred at +9 $\mathrm{km}$ this was the location of the Pudong New Area of Shanghai, which had a large RG area and therefore large LSI value (Fig. 2e).

The large values of AWMSI mainly occurred at -16 to $-10 \mathrm{~km},-3$ to $+2 \mathrm{~km}$ and +8 to $+12 \mathrm{~km}$ because urbanization and government planning policy had resulted in patch shapes having greater complexity (Fig. 2f). Although PR and PSCV did not exhibit obvious gradient characteristics along the east-west belt transect gradient (Figs. 2a and $2 d$ ), they both showed increased fluctuation (and a zigzag trend) as the spatial extent of the analytical windows decreased (Fig. 2b). LSI progressively decreased, then 
progressive increased and finally progressively decreased again from west to east along the belt transect (Fig. 2e). The highest value of LSI occurred at $-16 \mathrm{~km}$ from the city center and another peak occurred at $+8 \mathrm{~km}$ because these were the locations of residential estates with large greening area and relevantly large dispersion.

Based on the change of spatial extent of the analytical windows and comprehensive analysis, PR, PD, MPS, PSCV, LSI and AWMSI fluctuated irregularly (with both increases and decreases of spatial extent) along the belt transect. Generally, when the window was large $(\geq 5 \mathrm{~km})$, the changes in landscape metrics were gradual along the belt transect and exhibited smooth trend lines. When the window was small $(\leq 4 \mathrm{~km})$, the landscape metrics fluctuated dramatically. Therefore, a spatial extent of $5 \mathrm{~km}$ was deemed to be an appropriate scale for the gradient analysis of Shanghai green space landscape pattern. This size of analytical window not only avoided large fluctuations in the landscape metrics, but also comprehensively reflected the pattern of change of the urban green space landscape gradient.

\section{Variation of urban green space types percent coverage along the land use transect at different spatial extents}

There was almost no distribution of AG along the belt transect gradient in the city and the percentage of $A G$ in the landscape increased sharply at $+10 \mathrm{~km}$ east of the origin, i.e. near the junction between the second ring road and third ring road (Fig. 3a).

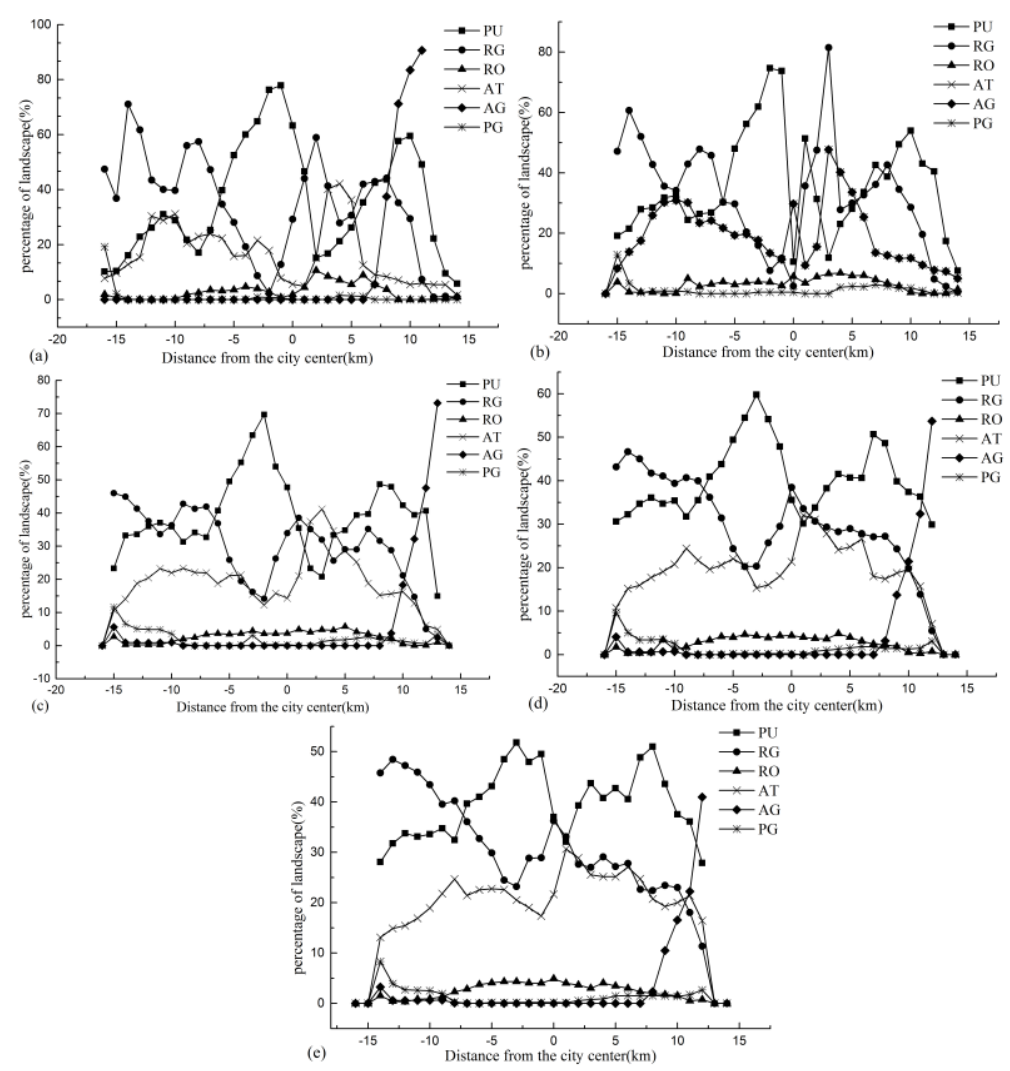

Figure 3. Variation in the proportions of Shanghai urban green space types along the east-west direction transect at different spatial extents: (a) $3 \mathrm{~km}$ extent, (b) $4 \mathrm{~km}$ extent, (c) $5 \mathrm{~km}$ extent, (d) $6 \mathrm{~km}$ extent, (e) $7 \mathrm{~km}$ extent. RO: roadside green space; PU: public park; RG: residential green space; AT: attached green space; AG: agricultural land; PG: production and protective green space 
The distribution of RG progressively decreased from west to east of the city with a low value within the range $-4 \mathrm{~km}$ to $-1 \mathrm{~km}$. PU progressively increased from the suburbs to the central urban area with the highest value at the central urban area; this type of green space exhibited an M-shaped distribution with peaks at $-4 \mathrm{~km}$ and +11 $\mathrm{km}$, and a valley at $+1 \mathrm{~km}$ to $+3 \mathrm{~km}$ (Figs. $3 a, 3 b, 3 c, 3 d$ and $3 e$ ). PG reached its highest peak between $-13 \mathrm{~km}$ and $-14 \mathrm{~km}$ from the center, and its proportion in the landscape was small between $-10 \mathrm{~km}$ to $+14 \mathrm{~km}$ from the center with sporadic distribution and a value close to 0 . AT generally exhibited an M-shaped distribution (Figs. 3a, 3b, 3c, 3d and $3 e$ ) and reached peak values at $-10 \mathrm{~km}$ to $-13 \mathrm{~km}$ and $+1 \mathrm{~km}$ to $+5 \mathrm{~km}$, with a sharp decrease to a valley at $-1 \mathrm{~km}$ to $+5 \mathrm{~km}$. RO changed in an irregular pattern, with a small proportion at both sides of the city and a large amount at $-10 \mathrm{~km}$ to $+8 \mathrm{~km}$.

Changes in the proportion of the landscape occupied by various green space types were closely related to the land utilization space pattern of Shanghai. The downtown area within the second ring is the political and business center of Shanghai; due to its early construction it mostly consisted of AT and PU with a small percentage of RO, and the green space types were not fragmented (Figs. $3 a, 3 b, 3 c, 3 d$ and $3 e$ ). When the spatial extent of the windows along the transect was $6 \mathrm{~km}$ and $7 \mathrm{~km}$, changes in the proportions of green space in the landscape along the belt transect exhibited a smooth trend line. However, when the extent was reduced to $3 \mathrm{~km}$ and $4 \mathrm{~km}$, the changes exhibited erratic fluctuations, indicating that the landscape metrics used in this research were sensitive to pattern changes when the spatial extent of windows used to identify them was small. Therefore, we concluded that the window size of $5 \mathrm{~km}$ was a proper extent for studying Shanghai's urban green space landscape pattern.

\section{Transect analysis using landscape-level metrics}

Figures 4 and 5 portray the variations in landscape metrics in the study area. The cross-section analysis from east to west and from south to north using a 5-km window showed that variations in the six major types of green space exhibited the same pattern. As a proportion of the landscape (PLAND), PU and AT exhibited an M-shaped distribution and the largest proportions of PU occurred at the city center and at $+9 \mathrm{~km}$ from the city center. The largest proportions of AT occurred at $+4 \mathrm{~km}$ and $+8 \mathrm{~km}$ from the city center, and PU mainly occurred between these two locations. The trends in the proportions of other categories of green space at the same distance from the city center were the same (Figs. $4 a$ and $4 b$ ). The patch density (PD) of the six major categories of urban green space was basically the same from east to west and from south to north (Figs. $4 c$ and $4 d$ ), and there was only some difference between PU and RO at $-5 \mathrm{~km}$ to $16 \mathrm{~km}$. However, at the landscape level, the overall PD trend of the six major categories of urban green space was the same (Fig. 5a).

The overall trend of the largest patch index (LPI) was also the same in the six major categories of urban green space, although there was some difference for PU at $-7 \mathrm{~km}$ to $-16 \mathrm{~km}$, and for AT at $+6 \mathrm{~km}$ to $+16 \mathrm{~km}$. However, at the landscape level, the distribution trend of LPI from east to west and from south to north was the same (Figs. $4 e, 4 f$ and $5 b$ ). The overall trend for LSI was the same in all green space types, but there was some small difference between PU and the other types at $-5 \mathrm{~km}$ to $-16 \mathrm{~km}$. At the landscape level, the distribution trend of LSI for the six major categories of urban green space was the same (Figs. $4 f, 4 g$ and $5 c$ ).

At the landscape level, the distribution trends of MPS and PSSD for the six major categories of urban green space from east to west and from south to north were the 
same, exhibiting exponential growth (Figs. $5 d$ and 5e). Furthermore, the distribution trends of AWMSI, AWMFD and SHDI were also the same (Figs. 5f, $5 g$ and 5h). To sum up, the distribution trends of the six major categories of urban green space in Shanghai were basically the same for both cross-sections and at the landscape level, which is characteristic of a "concentric circle" development pattern. Thus, these results provide further evidence that Shanghai's urban development can be described by the "concentric circle" urban development theory.
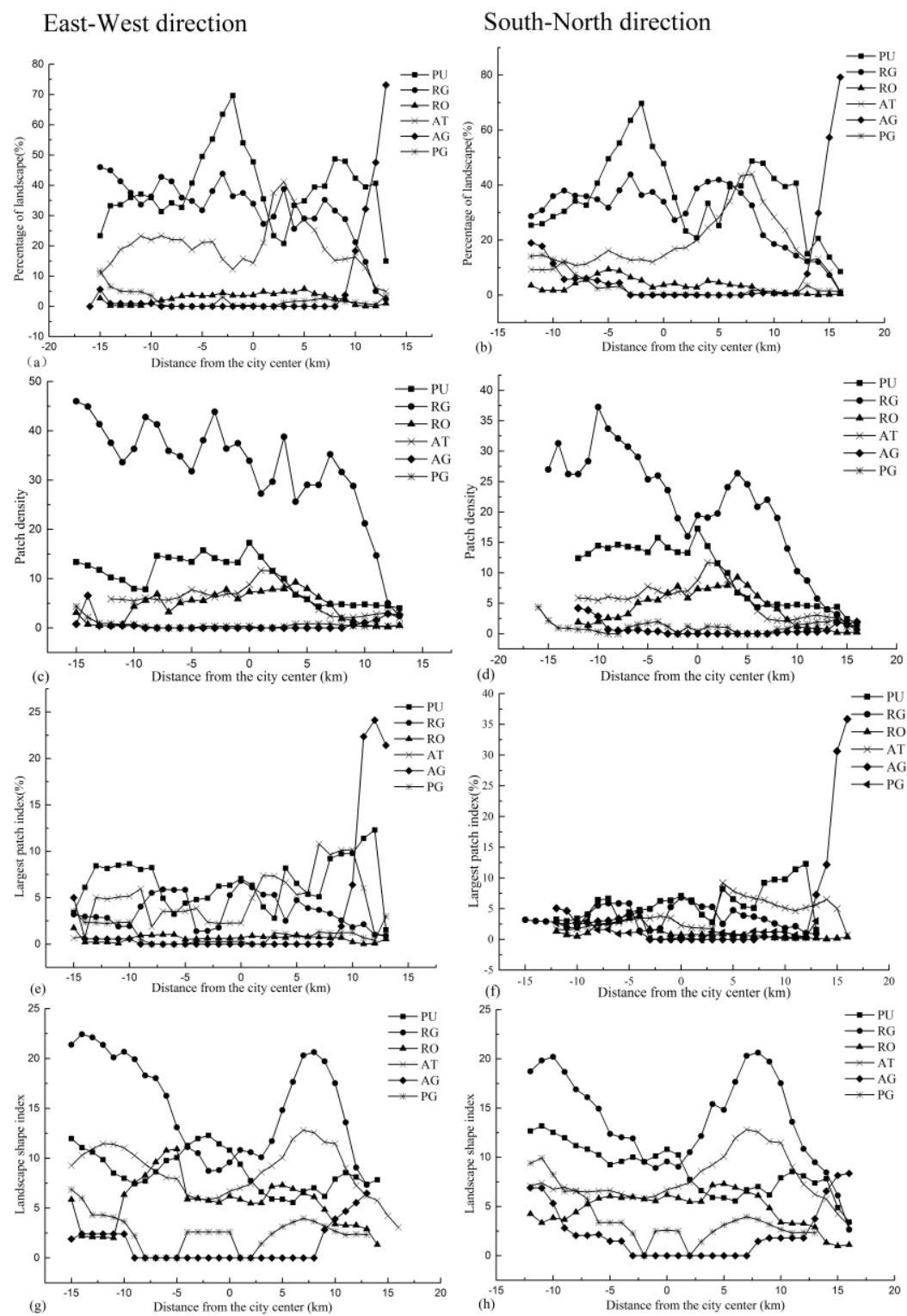

Figure 4. Gradient changes of landscape indices in different types of urban green space along east-west and south-north transects in Shanghai: ( $a$ and b) Percentage of landscape (\%); (c and

d) Patch Density (No. per 100 ha); (e and f) Largest patch index (\% total area); ( $g$ and $h$ )

Landscape shape index. RO: roadside green space; PU: public park; RG: residential green space; AT: attached green space; AG: agricultural land; $P G$ : production and protective green space 

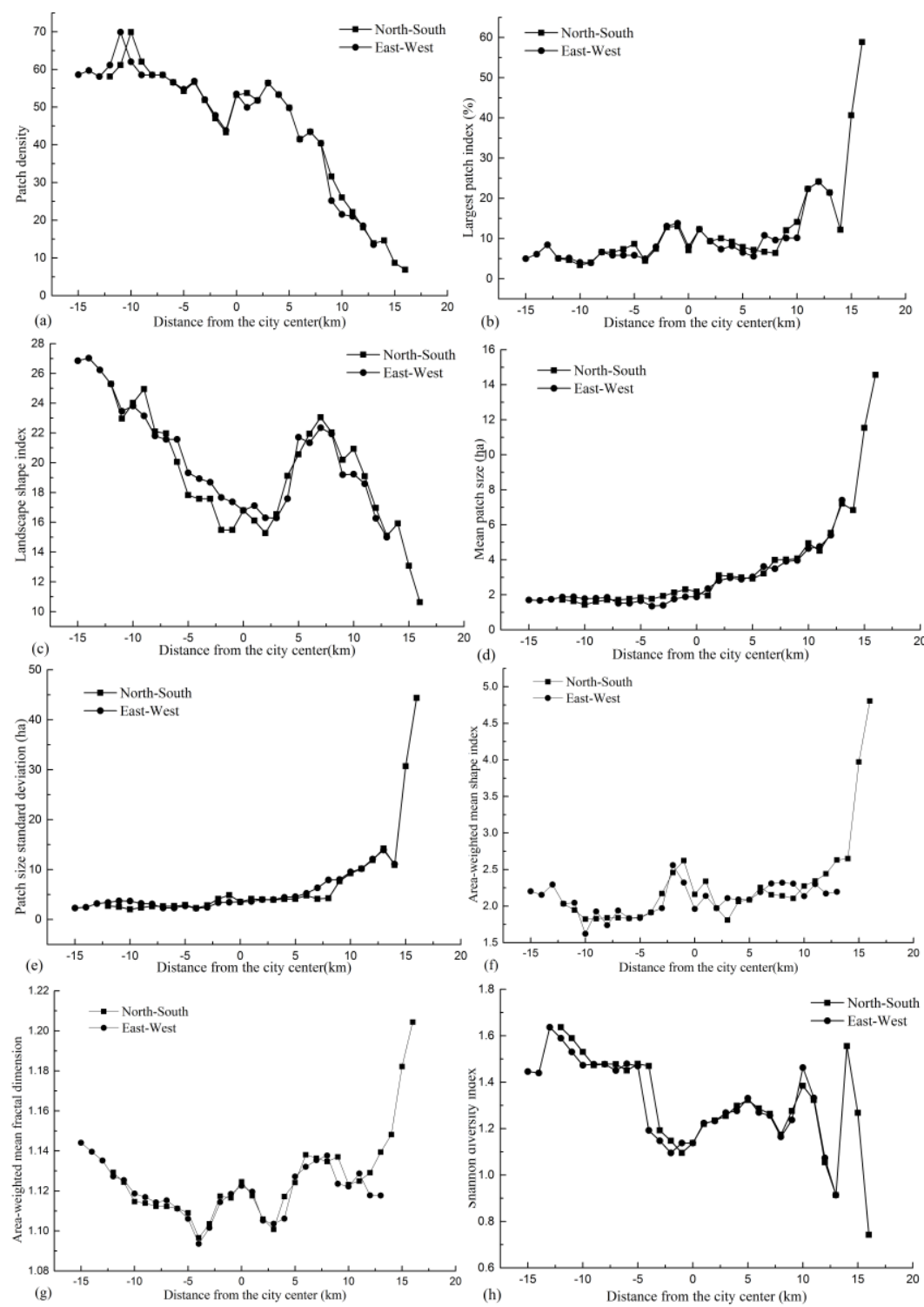

Figure 5. Gradient changes of urban green space at the landscape level: (a) Patch Density (No. per 100 ha); (b) Largest patch index (\% total area), (c) Landscape shape index; (d) Mean patch size (ha); (e) Patch size standard deviation (ha); $(f)$ Area-weighted mean shape index; $(g)$ Areaweighted mean fractal dimension; (h) Shannon diversity index

\section{Discussion}

\section{The reasonable extent for landscape pattern analysis}

The spatial resolution of remote sensing images and data processing accuracy have an effect on the identification of green space types and on research about landscape pattern changes (Turner, 1989; O'Neill et al., 1996; Baldwin et al., 2004; Wu, 2004; Buyantuyev and $\mathrm{Wu}, 2007$; Weng, 2007; Castilla et al., 2009). Therefore, the selection of high spatial resolution images and reasonable study amplitudes is vital to quantitative research of urban green land distribution patterns (Buyantuyev et al., 2010). In this study, we examined a range of reasonable spatial extents $(3,4,5,6$ and $7 \mathrm{~km})$ by which 
to analyze Shanghai's urban green land landscape pattern. The results showed that $5 \mathrm{~km}$ was the most suitable size of window, which corroborates the research findings of Shenyang (Tang, 2008).

Moreover, the spatial resolution of remote sensing images that suits the research on urban green land landscape pattern amplitude is determined by characteristics of the research area, by researchers' caution and by the analytical methods applied. According to our research, the spatial resolution of Landsat images (30 meters) was sufficient to determine the key information about urban green land needed in the research. For instance, LPS, AWMFD and SHDI (Figs. 5c, $5 g$ and $5 h$ ) indicated that the green land area from the suburban district inward to the downtown area of Shanghai was increasing while the patch density was decreasing. This pattern reflects the fact that the government has put emphasis on the provision of urban green land and has made a reasonable plan for the city. The method that combines the use of FRAGSTATS, GIS analysis and landscape indices provides significant guidance for further research about urban landscape patterns and town planning.

However, some uncertainty and a use of subjective factors is involved when considering the impact of the "background" land uses and edge effects during execution of the moving window procedure, sampling methods, and the selection of landscape metrics at different periods. Yet, little thought is given to the combination of the moving window procedure, landscape metrics and transfer matrix method of quantification. Therefore, classification training, revision of parameters and mathematical modeling should be conducted according to the characteristics of different research areas so as to increase the analysis accuracy and the degree to which research methods are integrated.

\section{The theories of urban development}

Dietzel et al. (2005) proposed a "concentric" model to describe urban development. Under this model, urban growth starts with the expansion of urban core areas and diffuses from these core areas outward. Urbanization in the Shanghai metropolitan region has resulted in dramatic increases in patch density, edge density, and patch and landscape shape complexity, as well as sharp decreases in both the largest and mean patch sizes, agricultural area, and landscape connectivity (Figs. 4 and 5). The general pattern of urbanization revealed in this study was that the increasingly urbanized landscape became compositionally more diverse, geometrically more complex, and ecologically more fragmented. This pattern is consistent with those in Phoenix and Las Vegas, USA as reported by $\mathrm{Wu}$ et al. (2011). First, both 32-km long and 7-km wide west-east and south-north transects in this study provided an excellent opportunity for characterizing broad-scale landscape pattern change along a rural-urban-rural environmental gradient; this has not been reported previously in any Chinese city. The urbanization gradient revealed by our transect analysis seemed to suggest that the different types of urban green space that are located different distances away from the downtown center can reflect different types of land-use. Therefore, land-use regularly ranges from the suburban agricultural land to public land to residential land, and then again to public land and residential land (Figs. 4a and 4b). The classic concentric zone urban development theory seems to account adequately for the land use pattern of the Shanghai metropolitan region up to the year 2015, and this is partly because classic theories of urban morphology such as the "concentric circle" theory were developed based primarily on studies of old and well-established cities (i.e., Chicago, San Francisco and Boston in the USA). 
Shanghai was growing rapidly in the beginning of the 21 st century, which may be indicative of a fast-growing city, or urban development among Chinese coastal cities. Perhaps a new urban development theory will be proposed in the near future that is more suitable for understanding the metropolitan area of Shanghai urbanization development.

In particular, combining gradient analysis with landscape metrics, as illustrated in this study, can help to quantitatively identify and characterize the gradients and complex spatial pattern of urbanization, which can subsequently be related to ecological and socioeconomic processes (McDonnell et al., 1997). The expansion of this study to understand the mechanism of urban landscape pattern formation requires a more comprehensive study. (e.g., Luck et al., 2001).

\section{Conclusions}

The method that combines the use of FRAGSTATS software, GIS analysis and landscape indices provides a completely new way of thinking and methodology for the analyzing the gradient of urban green landscape from an urban area to a suburban area. Meanwhile, this technique also promotes the analysis and quantitative research of landscape ecology (Herold et al., 2003; Sawaya et al., 2003; Garrigues et al., 2006).

"Windows" of different spatial extents were applied in this study to determine the one most reasonable for analyzing Shanghai's urban green space. Results confirm that the range of $5 \mathrm{~km}$ is the most suitable for research on Shanghai green landscape gradient analysis. Analysis at this scale not only avoids erratic changes in landscape indices, but also accurately identifies how urban green land types vary as the gradient changes. At the same time, a window of $5 \mathrm{~km}$ shows the significant "spatial characteristics" of urban green land changes with the different gradients.

Urban green landscape pattern can corroborate spatial development patterns, confirming that Shanghai urban development represents a mode of concentric circles. This conclusion relates closely to the leading urban development policies, and the coherence of urban land space and urban sustainable development.

\section{REFERENCES}

[1] Allen, P. M., Sanglier, M. (1979): A dynamic model of urban growth: II. - Social Biol. Struct. 2(4): 269-278.

[2] Batty, M., Longley, P., Fotheringham, S. (1989): Urban growth and form: Scaling, fractal geometry, and diffusion-limited aggregation. - Environ. and Plann. A: Economy and Space 21(11): 1447-1472.

[3] Batty, M. (1997): Cellular automata and urban form: A primer. - J.Amer. Plann. Assoc. 63(2): 266-274.

[4] Baldwin, D. J. B., Weaver, K., Schnekenburger, F., Perera, A. H. (2004): Sensitivity of landscape pattern indices to input data characteristics on real landscapes: implications for their use in natural disturbance emulation. - Landscape Ecol. 19(3): 255-271.

[5] Breuste, J., Feldmann, H., Uhlmann, O. (1998): Urban Ecology. - Springer, Berlin.

[6] Buyantuyev, A., Wu, J. (2007): Effects of thematic resolution on landscape pattern analysis. - Landscape Ecol. 22(1): 7-13.

[7] Buyantuyev, A., Wu, J., Gries, C. (2010): Multi scale analysis of the urbanization pattern of the Phoenix metropolitan landscape of USA: time, space and thematic resolution. Landscape Urban Plann. 94(34): 206-217. 
[8] Castilla, G., Larkin, K., Linke, J., Hay, G. (2009): The impact of thematic resolution on the patch-mosaic model of natural landscapes. - Landscape Ecol. 24(1): 15-23.

[9] Chatterjee, D. K. (1987): World Commission on Environment and Development. - Our Common Future. Oxford, New York.

[10] Chiesura, A. (2004): The role of urban parks for the sustainable city. - Landscape Urban Plann. 68: 129-138.

[11] Christaller, W. (1933): Central Places in Southern Germany. - Prentice Hall, Englewood Cliffs, New Jersey, USA.

[12] Couclelis, H. (1985): Cellular worlds: A framework for modeling micro-macro dynamics. - Environ. Plann. A. 17: 585-596.

[13] Dietzel, C., Herold, M., Hemphill, J. J., Clarke, K. C. (2005): Spatio-temporal dynamics in California's Central Valley: empirical links to urban theory. - International Journal of Geographical Information Science 19(2): 175-195.

[14] Frohn, R. C. (1998): Remote Sensing for Landscape Ecology: New Metric Indicators for Monitoring, Modeling, and Assessment of Ecosystems. - Lewis Publishers, Boca Raton.

[15] Garrigues, S., Allard, D., Baret, F., Weiss, M. (2006): Quantifying spatial heterogeneity at the landscape scale using. - Remote Sense. Environ 103(1): 81-96.

[16] Gordon, D. (1990): Green Cities: Ecologically Sound Approaches to Urban Space. Black Rose Books Press, Montreal.

[17] Harris, C. D., Ullman, E. L. (1945): The nature of cities. - Ann. Am. Acad. Polit. So. Sci. 242: 7-17.

[18] Herold, M., Goldstein, N. C., Clarke, K. C. (2003): The spatiotemporal form of urban growth: Measurement, analysis and modeling. - Remote Sense Envion. 86: 286-302.

[19] Hobbs, E. R. (1988): Species richness of urban forest patches and implications for urban landscape diversity. - Landscape Ecol. 1: 141-152.

[20] Hoyt, H. (1939): The Structure and Growth of Residential Neighborhoods in American Cities. - Federal Housing Administration, Washington, DC, USA.

[21] Kong, F., Nobukazu, N. (2006): Spatial-temporal gradient analysis of urban green spaces in Jinan, China. - Landscape and urban planning. 78(3) :147-164.

[22] Kowarik, I. (1990): Some responses of flora and vegetation to urbanization in Central Europe. - In: Sukopp, H., Hejný, S., Kowarik, I. (eds.) Urban ecology: Plants and plant communities in urban environments. SPB Academic, The Hague, 45-74.

[23] Li, H., Reynolds, J. F. (1994): A Simulation Experiment to Quantify Spatial Heterogeneity in Categorical Maps. - Ecology 75(8): 2446-2455.

[24] Li, J., Wang, Y., Shen, X., Song, Y. (2004): Landscape pattern analysis along an urbanrural gradient in the Shanghai metropolitan region. - Acta Ecologica Sinica 24(9): 19731980. (in Chinese).

[25] Lösch, A. (1954): The Economics of Location. - Yale University Press, New Haven, Connecticutt, USA.

[26] Luck, M., Wu, J. (2002): A gradient analysis of urban landscape pattern: a case study from the Phoenix region, Arizona, USA. - Landscape Ecol. 17(4): 327-339.

[27] Luck, M. A., Jenerette, G. D., Wu, J., Grimm, N. B. (2001): The urban funnel model and spatially heterogeneous ecological footprint. - Ecosystems 4(8): 782-796.

[28] McDonnell, M. J., Pickett, S. T. A., Groffman, P., Bohlen, P., Pouyat, R. V., Zipperer, W. C., Parmelee, R. W., Carreiro, M. M., Medley, K. (1997): Ecosystem processes along an urban-to-rural gradient. - Urban Ecosys. 1(1): 21-36.

[29] McGarigal, K., Marks, B. J. (1995): FRAGSTATS: Spatial pattern analysis program for quantifying landscape structure. - US Forest Service General Technical Report PNW., 351: I-IV, $122 \mathrm{p}$.

[30] McGarigal, K. (2002): Comparative evaluation of experimental approaches to the study of habitat fragmentation effects. - Ecological Applications 2: 335-345. 
[31] McGarigal, K., Cushman, S. A. (2008): The Gradient Concept of Landscape Structure: Or, Why are there so many patches. - http: www.umass.edu /landeco/ /mcgarigal.cushman.2005.pdf.

[32] Ministry of Construction, PR China. (2002): Standard for Classification of Urban Green Space. - CJJ/T 85-2002, Beijing. (in Chinese).

[33] O’Neill, R. V., Krummel, J. R., Gardner, R. H., Sugihara, G., Jackson, B., DeAngelis, D. L., Milne, B. T., Turner, M. G., Zygmunt, B., Christensen, S. W., Dale, V. H., Graham, R. L. (1988): Indices of landscape pattern. - Landscape Ecol. 1(3): 153-162.

[34] O’Neill, R. V., Hunsaker, C. T., Timmins, S. P., Jackson, B. L., Jones, K. B., Riitters, K. H., Wickham, J. D. (1996): Scale problems in reporting landscape pattern at the regional scale. - Landscape Ecology 11(3): 169-180.

[35] O’Neill, R. V., Riitters, K. H., Wickham, J. D., Jones, B. K. (1999): Landscape pattern metrics and regional assessment. - Ecosystem Health 5: 225-233.

[36] Pickett, S. T. A., Burch, J., Dalton, S. E., Foresman, T. W. (1997): A conceptual framework for the study of human ecosystems in urban areas. - Urban Ecosys. 1: 185199.

[37] Pickett, S. T. A., Cadenasso, M. L., Grove, J. M., Nilon, C. H., Pouyat, R. V., Zipperer, W. C., Costanza, R. (2001): Urban ecological systems: linking terrestrial ecological, physical, and socioeconomic components of metropolitan areas. - Annual Review of Ecology and Systematics 32: 127-157.

[38] Portugali, J. (2000): Self-Organization and the City. - Springer, Berlin.

[39] Pouyat, R. V., McDonnell, M. J. (1991): Heavy metal accumulations in forest soils along an urban-rural gradient in southeastern New York, USA. - Water Air Soil Pollut. 57: 797807.

[40] Pouyat, R. V., McDonnell, M. J., Pickett, S. T. A. (1995): Soil characteristics in oak stands along an urban-rural land-use gradient. - J.Environ. Qual. 24: 516-526.

[41] Sawaya, K. E., Olmanson, L. G., Heinert, N. J., Brezonik, P. L., Bauer, M. E. (2003): Extending satellite remote sensing to local scales: Land and water resource monitoring using high-resolution imagery. - Remote Sense Envion. 88(1-2): 144-156.

[42] Schell, L. M., Ulijaszek, S. J. (1999): Urbanism, Health and Human Biology in Industrialized Countries. - Cambridge University Press, Cambridge.

[43] Schweitzer, F. (1997): Self-Organization of Complex Structures. - Gordon and Breach, Amsterdam, Netherlands.

[44] Sukopp, H., Hejny, S., Kowarikeds, I. (1990): Urban ecology: plants and plant communities in urban environments. - The Hague, Netherlands: SPB Academic Publishing, 45-74.

[45] Sukopp, H. (1998): Urban ecology scientific and practical aspects. - In: Breuste, J., Feldmann, H., Uhlmann, O. (eds.) Urban ecology. Berlin: Springer. 3-16.

[46] Tang, L. (2008): Effects of Spatial Extent in Gradient Analysis of Shenyang Urban Green Space Patterns. - Resources science 30: 1415-1420. (in Chinese).

[47] Tobler, W. R. (1979): Cellular geography. - In: Gale, S., Olsson, G. D. (eds.) Philosophy in Geography. Reidel Publishing Company, Dordrecht, The Netherlands, 379-386.

[48] Turner, M. G. (1989): Landscape ecology: the effect of pattern on process. - Ann. Rev. Ecol. Syst. 20: 171-197.

[49] Von Thünen, J. H. (1825): Der Isolierte Staat in Beziehung auf Landwirtshaft and Nationalökonomie. - Hamburg, Rostock, Germany.

[50] Weng, Y. C. (2007): Spatiotemporal changes of landscape pattern in response to urbanization. - Landscape Urban Plann. 81: 341-353.

[51] White, R., Engelen, G. (1993): Cellular automata and fractal urban form: a cellular modelling approach to the evolution of urban land-use patterns. - Environ. Plann. A 25: 1175-1199. 
[52] Whitford, V., Ennos, V. A. R., Handley, J. F. (2001): City form and natural process indicators for the ecological performance of urban areas and their application to Merseyside, UK. - Landscape Urban Plann. 57: 91-103.

[53] Whittaker, R. H. (1975): Communities and Ecosystems. - MacMillan, New York.

[54] Wilson, A. G. (1976): Catastrophe theory and urban modelling: An application to modal choice. - Environment Plann. A 8: 351-356.

[55] Wilson, A. G. (1981): Catastrophy Theory and Bifurcation. - Univ. of California Press, Berkeley, California, USA.

[56] Wong, D. S. S., Fotheringham, A. S. (1990): Urban systems as examples of bounded chaos: Exploring the relationship between fractal dimension, rank-size, and rural-to-urban migration. - Geografiska Annaler 72B: 89-99.

[57] Wu, J. (2000): Landscape Ecology: Pattern, Process, Scale and Hierarchy. - Higher Education Press, Beijing.

[58] Wu, J. G. (2004): Effects of changing scale on landscape pattern analysis: Scaling relations. - Landscape Ecol. 19: 125-138.

[59] Wu, J., Jenerette, G. D., Buyantuyev, A., Redman, C. L. (2011): Quantifying spatiotemporal patterns of urbanization: the case of the two fastest growing metropolitan regions in the United States. - Ecological Complex 8(1): 1-8.

[60] Zhang, J., Wu, Z., Lu, Z. (2008): Extent effect of landscape gradient analysis of urbanrural transect. - Chinese Journal of Ecology 27(6): 978-984. ( in Chinese).

[61] Zhang, L. Q., Wu, J. P., Zhen, Y., Shu, J. (2004): A GIS-based gradient analysis of urban landscape pattern of Shanghai metropolitan area, China. - Landscape Urban Plann. 69: 116.

[62] Zhu, W., Carreiro, M. M. (1999): Chemoautotrophic nitrification in acidic forest soils along an urban-to-rural transect. - Soil Biol. Biochem.: 1091-1100.

[63] Zhu, M., Xu, J. G., Li, J. L., Xu, S., Song, L. G. (2006): Effects of spatial extent in gradient analysis of Shanghai City landscape pattern. - Chinese Journal of Ecology 25(10): 1214-1217. ( in Chinese). 